\title{
Mobilidade InTeRnacional EM Tempos De Pandemia
}

\author{
INTERNATIONAL MOBILITY IN PANDEMIC TIMES \\ MOVILIDAD INTERNACIONAL EN TIEMPOSDE PANDEMIA
}

\section{Josane do Nascimento Ferreira Cunha (iD) 9}

Doutoranda em Educação em

Ciências e Matemática

(REAMEC/UFMT)

Professora no Instituto Federal de

Mato Grosso (IFMT)

josanenf@gmail.com

\section{Irene Cristina de Mello (iD) 9}

Doutora em Educação (USP)

Professora da Universidade

Federal de Mato Grosso (UFMT)

Professora da Rede Amazônica de

Educação em Ciências e

Matemática (REAMEC)

ireneufmt@gmail.com

\section{Abdeljalil Akkari \\ iD 9}

Pós-doutorado pela Universidade de Baltimore (Estados Unidos),

Doutor em Ciências da Educação

pela Universidade de Genebra

(Suíça)

Professor da Universidade de

Genebra (Suíça)

djali198@gmail.com

\begin{abstract}
Resumo
Este artigo objetivou discutir a internacionalização nas Universidades, em tempos de pandemia e ensino online, a partir da perspectiva de especialistas e pesquisadores da área. A pesquisa é exploratória com abordagem qualitativa e a análise dos dados ocorreu por meio da indução analítica e triangulação. Os resultados indicam que a internacionalização do Ensino Superior tem ocorrido por meio do intercâmbio e mobilidade acadêmica virtual, considerado uma oportunidade decorrente da pandemia, pois possibilita uma formação internacional e intercultural para uma quantidade maior de participantes. Em relação aos desafios inerentes à mobilidade virtual, as Instituições de Ensino devem atuar com protagonismo, de forma organizada e estratégica para conseguir superar a crise, implementando ações de internacionalização e se beneficiando dos ambientes virtuais. Ademais, o apoio governamental, infraestrutura adequada e a formação de professores aparecem como elementos importantes para conseguir superar a não presencialidade e atingir os objetivos da internacionalização no ensino online.
\end{abstract}

Palavras-chave: Internacionalização do Ensino Superior. Mobilidade internacional. Aprendizagem Virtual.

Recebido em: 1 de dezembro de 2021.

Aprovado em: 2 de fevereiro de 2022.

Como citar esse artigo (ABNT):

CUNHA, Josane do Nascimento Ferreira; MELLO, Irene Cristina de; AKKARI, Abdeljalil. Mobilidade Internacional em tempos de Pandemia. Revista Prática Docente, v. 7, n. 1, e006, 2022. http://doi.org/10.23926/RPD.2022.v7.n1.e006.id1376 


\section{Abstract}

This article aimed to discuss internationalization in universities, in times of pandemic and online education, from the perspective of experts and researchers in the area. The research is exploratory with a qualitative approach and data analysis occurred through analytical induction and triangulation. The results indicate that the internationalization of higher education has occurred through exchange and virtual academic mobility, considered an opportunity arising from the pandemic, because it enables an international and intercultural training for a larger number of participants. In relation to the challenges inherent to virtual mobility, the Educational Institutions must act with protagonism, in an organized and strategic way to overcome the crisis, implementing internationalization actions and benefiting from virtual environments. Moreover, governmental support, adequate infrastructure, and teacher training appear as important elements to overcome the non-presence and achieve the objectives of internationalization in online education.

Keywords: Internationalization of Higher Education. International Mobility. Virtual Learning.

\section{Resumen}

Este artículo tiene como objetivo discutir la internacionalización en las universidades, en tiempos de pandemia y de educación en línea, desde la perspectiva de expertos e investigadores. La investigación es exploratoria con abordaje cualitativo y el análisis de los datos se realizó mediante inducción analítica y triangulación. Los resultados indican que la internacionalización se ha dado a través del intercambio y la movilidad académica virtual, considerada una oportunidad derivada de la pandemia, ya que permite una formación internacional e intercultural para más participantes. En relación con los retos de la movilidad virtual, las Instituciones Educativas deben actuar con protagonismo, de forma organizada y estratégica para superar la crisis, implementando acciones de internacionalización y beneficiándose de los entornos virtuales. Además, el apoyo gubernamental, la infraestructura adecuada y la formación de los profesores aparecen como elementos importantes para superar la no presencia y lograr los objetivos de la internacionalización en la educación en línea.

Palabras clave: Internacionalización de la Educación Superior. Movilidad Internacional. Aprendizaje virtual. 


\section{INTRODUÇÃO}

O processo de internacionalização do Ensino Superior intensificado com o fenômeno da globalização ganhou destaque a partir da década de 1990 em função de suas múltiplas possibilidades consideradas benéficas para as Universidades. Entre essas, a possibilidade da integração intercultural de redes colaborativas, que tendem a fortalecer as competências científicas, e que está diretamente relacionada com a qualidade e excelência das Instituiçõos de Ensino Superior (MOROSINI, 2014; MOROSINI; NASCIMENTO, 2017).

Um dos propósitos fundamentais da internacionalização do Ensino Superior é aperfeiçoar a capacitação de docentes e estudantes para viver em um mundo globalizado. Esse processo pode ocorrer por meio da mobilidade acadêmica internacional, internacionalização do currículo e internacionalização em casa. A mobilidade acadêmica internacional é uma das principais formas de realizá-la, tendo em vista que há uma imersão presencial do estudante na cultura do país estrangeiro, propiciando uma extensa e rica formação.

Segundo a Organização para a Cooperação e Desenvolvimento Econômico (OCDE, 2020), milhões de estudantes participaram dessa modalidade de internacionalização nos últimos anos, e estudos desta Organização apontavam um crescimento ainda maior nos anos seguintes. Dentre os programas de mobilidade acadêmica e intercâmbio, destaca-se no âmbito internacional o European Action Scheme for the Mobility of Students (ERASMUS), programa da União europeia, que possibilitou a mobilidade de mais de 9 milhões de estudantes durante os seus 30 anos de existência (CERI JONES, 2017).

A despeito das expectativas de expansão da internacionalização universitária, em 2020, o cenário se alterou, consideravelmente, em decorrência da pandemia do COVID-19, doença viral causada pelo Coronavírus SARS-CoV-2. A internacionalização mediante mobilidade acadêmica se depara com uma paralisação inesperada, o que preocupou os pesquisadores e especialistas da área. A pandemia, considerada a maior crise sanitária do século, teve seu início em dezembro na China e provocou problemas gravíssimos nas áreas da Saúde, da Economia, das Políticas Públicas e Sociais, entre outras. A área da Educação também foi muito afetada, com milhares de estudantes do mundo sem aulas presenciais em função do distanciamento social recomendado pela Organização Mundial de Saúde (OMS).

Diante dessa situação, o ensino online mediado pelas Tecnologias Digitais (TD) se tornou o principal meio para dar continuidade às atividades acadêmicas no mundo e minimizar os impactos causados pela pandemia. Em alguns países a Educação a Distância online já vem 
sendo realizada, e no Brasil desde os anos de 1990 com regulamentação específica disposta em documentos oficiais.

Em meio a uma crise sem precedentes para o campo de internacionalização universitária, muitos debates e discussões sobre a internacionalização do Ensino Superior têm sido realizados por pesquisadores da área mediante os webinars (seminários online), lives na plataforma do Youtube e outras redes sociais, no intuito de refletir, compartilhar experiências e encontrar soluções para minimizar e prosseguir com as ações da internacionalização. Nes sa direção, surge o seguinte questionamento: quais os desafios e perspectivas da mobilidade internacional em tempos de pandemia?

Sabe-se que a internacionalização e o ensino online já vêm sendo realizados há algum tempo, logo não são considerados novidades, porém a internacionalização, em tempos de ensino remoto, é uma temática atual com poucas pesquisas relacionadas ao assunto. Apesar de já existir programa de intercâmbio virtual, não havia uma discussão tão intensa como a que está ocorrendo neste período pandêmico, em que a única possibilidade para seguir com as atividades de internacionalização é por meio do uso de Tecnologias Digitais.

O presente artigo tem como objetivo engendrar um debate sobre as possibilidades da mobilidade internacional em tempos de pandemia, em que a internacionalização passa por importantes ressignificações. Poderia se discutir aqui várias categorias de internacionalização, como por exemplo: as patentes, as cooperações internacionais, entre outras, todavia este estudo explora a mobilidade acadêmica.

\subsection{INTERNACIONALIZAÇÃO DO ENSINOSUPERIOR}

A internacionalização em função da pesquisa já vinha sendo realizada nas Universidades mediante a participação independente dos professores pesquisadores, porém no que concerne à função ensino, o processo era dificultado em razão de ser gerido pelo Estado, o que foi modificado a partir da globalização (MOROSINI, 2006; STALLIVIERI, 2017). A partir de então, Morosini e Nascimento (2017, p. 2) afirmam que "a internacionalização da Educação Superior vem se constituindo em um dos principais motes da Universidade na contemporaneidade, destacando-se a contribuição positiva dessa presença".

No Brasil, entre 2009 e 2013, a produção sobre internacionalização era muita baixa, não ultrapassava o número de 23 monografias estudadas por poucas Instituições, porém no decorrer dos anos a temática ganhou destaque e se expandiu em função de sua relevância como exposto na citação anterior (MOROSINI; NASCIMENTO, 2017). Essa expansão também pôde ser 
percebida pelo aumento das atividades de: cooperação internacional, mobilidade acadêmica, publicações em revistas internacionais e participação em eventos no ex terior (STALLIVIERI, 2017).

A internacionalização é considerada uma temática interdisciplinar estudada por várias áreas como a Educação, Educação em Ciências, Administração, Relações Internacionais, Linguística, entre outras. No contexto internacional, a definição mais utilizada é a de Jane Knight, em que afirma que a internacionalização é "o processo que integra uma dimensão global, intercultural e internacional nos objetivos, funções e oferta da educação pós -secundária" (KNIGHT, 2004, p. 11). Já no contexto nacional, Morosini (2017) define como:

Processo de integrar uma dimensão internacional e intercultural na Educação Superior, advindo de interações, sustentadas por redes colaborativas, com blocos socioeconômicos desenvolvidos e com outros que valorem múltiplas culturas, diferenças, locais e tempos, fortalecendo a capacidade científica nacional, com o fito de ser irradiador do desenvolvimento sustentável (MOROSINI, 2017, s.p).

As Instituições de Ensino Superior têm procurado investir no processo de internacionalização com o intuito de ganhar visibilidade global e, com isso, ampliar suas redes de cooperação e colaboração internacional, propiciando uma formação holística e intercultural aos servidores e estudantes, além de fortalecer suas ações e elevar a qualidade educacional.

Segundo Knight (2012), a internacionalização pode ser realizada por meio da internacionalização no exterior, que se refere a todos os meios de mobilidade, e pela internacionalização em casa, que abrange atividades interculturais e internacionais no contexto local dos estudantes.

A mobilidade acadêmica é considerada um dos pilares mais importantes da internacionalização. Segundo Ramos (2018, p. 5): “a mobilidade internacional de estudantes é uma estratégia de internacionalização mais disseminada entre as IES no mundo, que têm aplicado cada vez mais recursos financeiros em programas de estudos no exterior e recrutamento de estudantes internacionais". Não é incomum nas Universidades que docentes e discentes reduzam a internacionalização ao processo de mobilidade.

No Brasil, a internacionalização das Instituições de Ensino Superior foi fortalecida de modo expressivo com o programa de mobilidade acadêmica internacional Ciências sem Fronteiras. O que oportunizou a inserção de várias Instituições de Educação no cenário global, incentivou as parcerias com instituições internacionais renomadas, elevando as oportunidades de mobilidade acadêmica para os estudantes e professores, em outras palavras, acelerou o processo de internacionalização do Ensino Superior (STALLIVIERI, 2020b). O encerramento 
do programa Ciências sem Fronteiras interrompeu diversas parcerias, o que causou a interrupção ou redução das atividades internacionais, impactando diretamente na mobilidade internacional, conforme autora supracitada.

No ano de 2017 ocorreu o lançamento do programa CAPES-Print de internacionalização Institucional, uma outra oportunidade para as Instituições de Ensino Superior elevarem o nível de internacionalização, porém somente uma parcela mínima de institui ções foram beneficiadas, 36 Instituições, e mais de $90 \%$ não conseguiram participar do Programa, visto que não possuíam um plano de internacionalização considerado um dos requisitos básicos para o acesso (STALLIVIERI, 2020b).

O trabalho de Bittencourt (2019) evidenciou que entre os indicadores de avaliação da internacionalização na pós-graduação, sete estão vinculados à mobilidade acadêmica internacional, o que demonstra a sua relevância. Com o término do Programa Ciências sem Fronteiras e uma quantidade mínima de Instituições beneficiadas pelo CAPES-Print, somente uma parcela pequena de estudantes consegue participar deste tipo de mobilidade com garantias de cobertura dos custos. Outros problemas intrínsecos se somam à internacionalização, tais como: a falta de habilidades linguísticas dos estudantes brasileiros e de recursos financeiros, dificultando sobremaneira a mobilidade internacional.

Considerando essas dificuldades, pesquisadores da área de Educação Internacional apresentam outras dimensões da internacionalização do Ensino Superior, tais como: a internacionalização do currículo e a internacionalização em casa, com o intuito de incluir/beneficiar os demais estudantes e servidores das Instituições.

A internacionalização do currículo é definida como "a incorporação de dimensões internacionais, interculturais e/ou globais no conteúdo do currículo, bem como nos resultados da aprendizagem, tarefas de avaliação, métodos de ensino e serviços de apoio de um programa de estudo" (LEASK, 2015, p. 9). A internacionalização em casa "é a integração intencional da dimensão internacional e intercultural no currículo formal e informal para todos os estudantes em ambientes domésticos de aprendizagem" (BEELEN; JONES, 2015, p. 69). Em outros termos, "o ensino e aprendizagem internacional e intercultural no campus doméstico é o principal objetivo, independente da experiência do aluno ser potencializada pela mobilidade" (BEELEN; JONES, 2015, p. 63).

A internacionalização em casa pode ocorrer por meio de diversificadas atividades, tais como: literatura internacional comparativa e produzida em diferentes contextos, professores 
palestrantes locais e estrangeiros de instituições parceiras, criação de soluções compartilhadas para problemas comuns, recebimento de estudantes estrangeiros, apresentação de grupo cultural local e internacional, cursos de idiomas e interculturalidade, aproveitamento das experiências de estudante de mobilidade na instituição de origem, colaboração online, aprendizagem digital, mobilidade e intercâmbio virtual com instituições parceiras (BARANZELI; COSTA MOROSINI; WOICOLESCO, 2020; MACHADO; SANTOS ; COSTA, 2020; BARANZELI, 2019; JONES; REIFFENRATH, 2018; BEELEN; JONES, 2015).

Observa-se que as atividades de internacionalização do Ensino Superior, principalmente, a internacionalização em casa está diretamente conectada às tecnologias digitais. Para Santos (2020, p. 219): “as tecnologias digitais possibilitam a internacionalização na Educação Superior em casa ou ainda a internacionalização do currículo. Por meio da educação online diferentes oportunidades para o desenvolvimento de competências interculturais se apresentam".

Diante da relevância das tecnologias digitais no processo de internacionalização, e em período de pandemia, o ensino online se tornou a principal opção para manter as atividades acadêmicas no cenário global.

\subsection{ENSINO ONLINE E A INTERNACIONALIZAÇÃO DO ENSINOSUPERIOR}

A educação online se refere às ações de ensino e aprendizagem realizadas mediante tecnologia, como internet e videoconferências, com ampla abrangência desde a educação infantil à pós-graduação, que podem ocorrer de forma virtual em sua totalidade, semipresencial ou híbrida (MORAN, 2003). Com o avanço tecnológico, há um rompimento dos obstáculos temporais e espaciais, o que permite o desenvolvimento de cursos online, em que docente e discente podem interagir de forma síncrona ou assíncrona pelo bate papo ou chat (VALENTE, 2019).

De acordo com Rapanta et al. (2020), o ensino online é caracterizado pelo ensino e aprendizagem a distância, em que o acesso aos materiais ocorre por meio da tecnologia, há uma interação entre: material/estudante, estudante/estudante e estudante/professor, e conta com uma equipe de suporte que oferece apoio aos estudantes.

As tecnologias emergentes, como os smartphones, tablets, a Web 2.0 e 3.0 representam uma nova era no ambiente educacional virtual, o que alterou o perfil da aprendizagem online, permitindo que os estudantes pudessem construir e difundir seus materiais na internet de modo colaborativo e interativo, ou seja, possibilitando a formação de uma comunidade de 
aprendizagem, em que os estudantes e professores dialoguem e aprendam juntos (PALLOFF; PRATT, 2015).

O espaço virtual permite a democratização do ensino, oportunizando o acesso, o compartilhamento e a troca de experiências interculturais de pessoas dos mais distintos lugares do mundo. Possibilita também a ampliação da área de atuação das Instituições de Ensino, o que faz com que o intercâmbio e a cooperação internacional com Instituições de outros países ocorram propiciando a internacionalização do ensino (KENSKI, 2003). Para a autora, esse processo altera a estrutura e o sistema educativo, e serão necessárias algumas reestruturações como compatibilização do currículo, articulações com instituições internacionais, convênios, entre outros. Acrescenta ainda que:

\begin{abstract}
A internacionalização não pode deixar de ser acompanhada da valorização dos aspectos que caracterizam o caráter regional do ensino e do fortalecimento da cidadania, da solidariedade e do respeito entre os povos. Todos precisam se sentir como cidadãos de seu próprio país e cidadãos do mundo. Características como a cooperação, a interatividade e o respeito às diferenças são aspectos que precisam ser priorizados em todas as instâncias e em todos os setores educacionais. Nesse sentido, os professores precisam ser capacitados para orientar seus alunos (e a si mesmos) a aprender por meio de intercâmbios virtuais (e/ou presenciais) com alunos de diferentes culturas, idiomas e realidade social (KENSKI, 2003, p. 87).
\end{abstract}

Estes são aspectos fundamentais da internacionalização do Ensino Superior, que a propósito foram adequadamente sintetizados por Kenski, pois mostram o sentido deste processo.

O ensino online pode viabilizar a mobilidade acadêmica virtual e intercâmbio virtual, favorecendo a internacionalização como abordado na seção anterior, todavia são poucos os projetos dessa natureza no Brasil. Com a paralisação global das atividades educacionais em decorrência da pandemia do COVID-19, surgiu entre as várias problemáticas a preocupação com a internacionalização via mobilidade acadêmica presencial.

Muitos seminários e palestras online sobre essa temática têm sido realizados pelos pesquisadores da área por meio da plataforma Youtube e outras redes sociais, com o propósito de discutir, de compartilhar experiências e possibilidades de como amenizar os impactos causados pela pandemia. Dessa maneira, este estudo objetiva refletir sobre os desafios e possibilidades da mobilidade acadêmica no contexto de pandemia e ensino online.

\title{
2. Metodologia
}

O presente estudo se caracteriza como abordagem qualitativa, pois a investigação é descritiva e o foco principal está na valorização do processo do que simplesmente no produto 
(BOGDAN; BIKLEN,1994). A pesquisa é do tipo exploratória, pois visa se familiarizar com o fenômeno de mobilidade em tempos de ensino online.

A produção de dados ocorreu mediante a formulação de uma questão envolvendo as perspectivas e desafios da mobilidade internacional diante do ensino online, em tempos de pandemia. Esta foi enviada por meio de tecnologias digitais aos professores especialistas, pesquisadores e gestores da área de internacionalização da Educação Superior do Brasil e de algumas instituições estrangeiras. Muitos destes participantes são autores de obras consagradas na área de Educação Internacional. Utilizam-se, ainda, três textos referentes à temática em estudo e informações oriundas de uma webinar (seminário online) enviadas como respostas por três dos participantes.

Em relação às respostas, duas dessas precisaram ser transcritas com auxílio de ferramenta, pois foram enviadas por áudio. As respostas foram recebidas entre agosto e início de setembro de 2020, das cinco regiões do Brasil e três regiões do exterior, a saber: Boston College nos Estados Unidos, representante da Fundação Qatar em Doha e da Universidade de Genebra na Suíça. Os participantes foram denominados por códigos, na seção de análise de dados de acordo com o quadro a seguir:

Quadro 1 - Designação e localidade dos sujeitos participantes da pesquisa

\begin{tabular}{|l|l|}
\hline \multicolumn{1}{|c|}{ Código do sujeito } & \multicolumn{1}{|c|}{ Localidade (nacional e internacional) } \\
\hline PB1 & Pesquisador brasileiro da região Norte \\
\hline PB2 & Pesquisador brasileiro da região Nordeste \\
\hline PB3 & Pesquisador brasileiro da região Centro-Oeste \\
\hline PB4, PB4a, PB4b & Pesquisadores brasileiro da região Sul \\
\hline PB5 & Pesquisador brasileiro da região Sudeste \\
\hline PE1 & Pesquisador estrangeiro do Qatar \\
\hline PE2 & Pesquisador estrangeiro da Suíça \\
\hline PE3 & Pesquisador estrangeiro dos Estados Unidos \\
\hline
\end{tabular}

Fonte: Própria pesquisa.

Para a análise dos dados se utilizou a indução analítica, visto ser "um procedimento lógico que consiste em partir do concreto para chegar ao abstrato, delimitando as características essenciais de um fenômeno" (DESLAURIERS, 2008 p. 339). Essa técnica possibilita demonstrar os elementos fundamentais da pesquisa, e a partir disso deduzir uma explicação. 
No intuito de diminuir os vieses da pesquisa se realizou também a triangulação. A análise por triangulação de métodos pode ser efetuada por meio da articulação de três aspectos: os dados empíricos, diálogos com os autores e análise de conjuntura (MARCONDES; BRISOLA, 2014). Neste estudo, a triangulação ocorreu a partir da articulação entre as reflexões e os diálogos feitas com os teóricos da internacionalização do Ensino Superior, as respostas dos pesquisadores/especialistas da área das diferentes regiões do Brasil e do exterior e uma análise de conjuntura, conforme Figura 1.

Figura 1 - Ilustração da triangulação utilizada na pesquisa

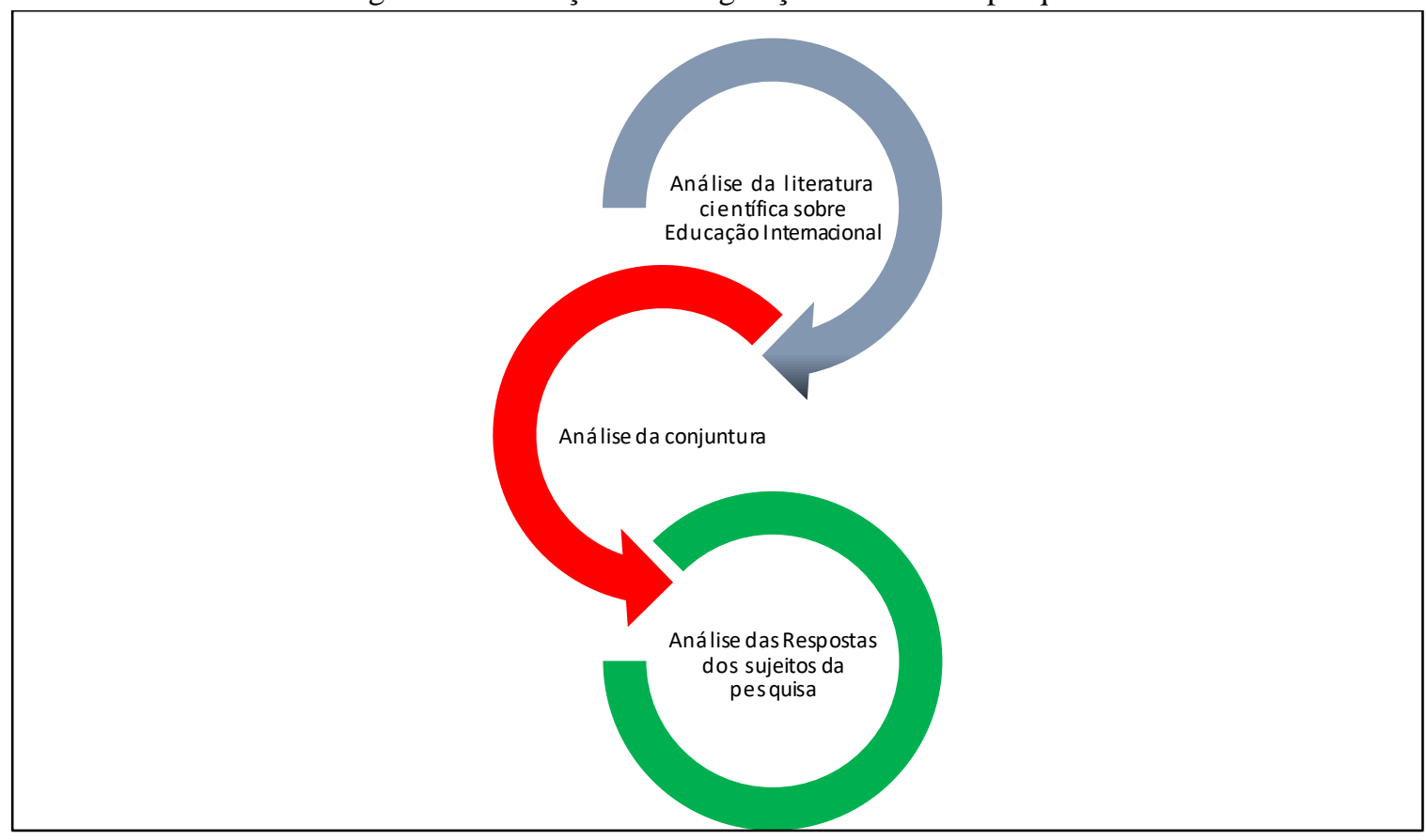

Fonte: Própria pesquisa.

\section{RESULTADOS E DISCUSSÕES}

$\mathrm{Na}$ sequência são apresentadas as análises dos dados relativos à entrevista com os professores especialistas e pesquisadores da área de internacionalização da Educação Superior, de acordo com duas categorias principais: sendo a primeira Mobilidade acadêmica internacional: perspectivas e oportunidades, e a segunda Desafios da Internacionalização via mobilidade acadêmica no contexto online. Estas duas categorias auxiliarão a compreender o problema deste artigo em questão.

\subsection{MOBILIDADE ACADÊMICA INTERNACIONAL: PERSPECTIVAS E OPORTUNIDADES}

A pandemia do COVID-19 afetou gravemente todos os setores da sociedade no cenário global, com impacto principalmente na área da educação, o que reverberou na 
internacionalização do Ensino Superior, particularmente na mobilidade acadêmica internacional. Uma vez que o distanciamento social foi estabelecido, conforme as orientações da Organização Mundial de Saúde (OMS, 2020), as Instituições de Ensino tiveram que suspender as atividades presenciais, com isso se interrompeu, provisoriamente, a mobilidade acadêmica internacional.

Muitos problemas surgiram deixando a comunidade acadêmica apreensiva como, por exemplo, estudantes em mobilidade que não conseguiam retornar ao Brasil. E, estudantes estrangeiros, em mobilidade no Brasil, tiveram a mesma dificuldade, nos casos em que as fronteiras foram fechadas, impedindo-os de regressarem. Muitas foram as dúvidas quanto aos procedimentos e os casos tiveram que ser resolvidos individualmente com cada parceiro internacional, mediante assessorias internacionais das Universidades, juntamente com embaixadas e disponibilização de recursos extras. Estudantes se mostravam com medo de perder a sua mobilidade ao retornar para o seu país de origem, enquanto seus familiares temiam pela segurança.

Muitas foram as dúvidas, como a de fazer a viagem de volta diante de uma pandemia e correr riscos nos deslocamentos ou permanecer em segurança no país em que estavam, sem garantia de quanto tempo precisariam esperar isolados. Cada Universidade reagiu de uma forma, tentando encontrar caminhos diplomáticos e seguros, por vezes mudando protocolos, regras de editais e normas. As associações internacionais e eventos internacionais clássicos também tiveram que rever suas atividades. Após o primeiro impacto de cancelamentos de atividades, muitas Instituições de Ensino Superior em tempos e formas diferentes, dependendo da localização geográfica, retomaram as atividades acadêmicas por meio do ensino online.

No Brasil também se percebeu esse impacto, porém como abordado na primeira seção do artigo, as Instituições já apresentavam algumas dificuldades, sobretudo financeiras para a realização das mobilidades acadêmicas, o que foi acentuada pela pandemia. Portanto, pesquisadores renomados da área, como Morosini (2017), Leask (2015), Beelen e Jones (2015), entre outros, já vinham discutindo outras possibilidades de internacionalização do Ensino Superior como a internacionalização do currículo e internacionalização em casa.

Em relação às perspectivas da internacionalização do Ensino Superior, em tempos de pandemia, verificou-se que a interrupção da mobilidade acadêmica e, possivelmente, uma diminuição desta ocorrerá em função da falta de recursos financeiros, o que foi sinalizado com preocupação por alguns dos pesquisados, que abordam as possíveis consequências, como por 
exemplo PE1, ao afirmar que "as perspectivas são difíceis de prever se não houver um progresso médico para o COVID-19, a mobilidade internacional será decrescente”. Já para PB2, "a perda desta oportunidade, que é muito individual, é a maior perda para as sociedades do mundo todo". Enquanto para PB5:

\begin{abstract}
A solidariedade entre os países, ao invés de aumentar, vai diminuir. As pessoas estão mais propensas à solidariedade, mas os estados, os paísesna relação uns com os outros tendem a diminuir em função dos recursos que ficaram mais escassos. A pandemia atinge diretamente a economia, ela vai fazer com que o estado elenque suas prioridades, obviamente a primeira é tentar fazer a roda da economia e isso vai ter impacto direto nas relações internacionais, principalmente, a mobilidade acadêmica. Outra coisa a ser levado em conta é a posição do Brasil nos rankings internacionais em termos de Educação Superior. O Brasil nunca foi um destino que os alunos estrangeiros escolhessem prioritariamente, está ainda no epicentro da pandemia. Então, o Brasil tem um conjunto muito ruim por assim dizer, a tempestade perfeita de coisas, as notícias sobre a gente lá fora são sempre muito negativas, nós temos todos os elementos para termos dificuldade, e isso para citar o Brasil apenas. A gente não tem esse protagonismo todo em pesquisa, não temos, por mais que as pessoas digam que sim, não é verdade, basta olhar para nossa colocação nos rankings. Enfim, isso tudo para o Brasil vai ser muito complicado (PB5).
\end{abstract}

Diante das situações apresentadas pelos pesquisados, é imprescindível a atuação dos governantes e das Instituições de Ensino Superior na tentativa de encontrar soluções para conseguir superar e diminuir o impacto dessa crise, são necessárias me didas enérgicas, todavia feitas com muita responsabilidade, sustentabilidade e reciprocidade, inclusão, compromisso social, itens estes pertencentes a então chamada internacionalização responsável (STALLIVIERI, 2018).

O apoio governamental é visto como crucial para dirimir os impactos na internacionalização do Ensino Superior, no entanto, no Brasil, as Instituições deverão encontrar dificuldades nesse sentido, uma vez que a área da Educação não parece ser prioridade e vêm padecendo com os cortes nos últimos anos. Outrossim, como apontado por um dos pesquisados, há uma visão negativa do Brasil perante a forma como está lidando com a pandemia. Portanto, as Instituições de Ensino Superior terão papel fulcral na tentativa de restabelecer a internacionalização do Ensino Superior. Como enfatizado por Stallivieri (2020a), as Universidades, geradoras de conhecimentos, precisarão agir com responsabilidade social e protagonismo na criação e condução dos projetos, capacitando e formando os seus servidores.

Nesse contexto se notou que a possibilidade de retomada da mobilidade acadêmica internacional ocorre por meio de ambiente online, que poderá ser efetuada pela cooperação internacional, intercâmbio e mobilidade virtual, desenvolvendo a então chamada 
internacionalização do currículo e internacionalização em casa. O que também foi constatado nas respostas dos pesquisados brasileiros:

A Pandemia traçou um divisor de águas na Mobilidade Internacional, abrindo oportunidades para o crescimento e ampliação da modalidade de Internationalization at Home, opção existente a partir de 2017, mas que sempre encontrou dentro das Universidades Federais, muitas resistências e falta de apoio institucional. De certa forma, forçou os gestores internacionais a refletir sobre esta proposta ino vadora e a reconsiderar a possibilidade de implantação da Mobilidade Internacional Virtual (PB1, grifo nosso).

Vejo que tentaremos a curto e médio prazo, substituir algumas experiências também importantes, como o aprendizado de conteúdos específicos, de língua estrangeira e de conhecimentos culturais, à distância, por meio da internet, mas que como perspectiva futura, não podemos perder de vista a realização da experiência presencial, para que possamos formar indivíduos cada vez mais conscientes de sua conexão com o mundo em que vive (PB2).

As perspectivas são muito boas, por incrível que pareça! Os intercâmbios online já eram uma realidade, porém não muito explorados. Podemos presenciar hoje uma infinidade de conexões internacionais no modo remoto. Projetos antes acontecendo de maneira mais lenta, ganharam velocidade e com muito engajamento pela comunidade acadêmica. Outro aspecto relevante, é o fácil acesso às plataformas. Estamos de fato tendo a oportunidade de experimentar um mundo sem fronteiras para um número muito maior de pessoas (PB3, grifo nosso).

Vamos ter que começar a praticar uma mobilidade virtual, ela já vem acontecendo e sendo proposta, e pelo menos no primeiro período ela vai talvez dominar e, depois, compartilhar com a mobilidade presencial. $O$ fato é que se por um lado a vivência e experiência e interação num país estrangeiro é muito rica, a gama de oportunidade que se abre com uma mobilidade virtual é muito maior. Então, muitos alunos que não teria nenhuma possibilidade de ir para outro país até por uma questão de custo, eles têm a possibilidade de se matricular num outro país numa disciplina, numa Universidade cooperada (PB4, grifo nosso).

Acho que o ensino virtual veio para ficar literalmente, num país da dimensão do Brasil, isso faz sentido, porque você pode se melhorar nos aparatos tecnológico, colocando à disposição de todas as classes sociais. Você pode levar de fato a informação de qualidade para todos os cantos do país, mas como eu disse é insubstituível a vivência presencial, eu espero que a gente recobre rapidamente a capacidade de transitar para lá e para cá, isso faz falta (PB5).

As respostas dos pesquisados estrangeiros estão na mesma linha de raciocínio de acordo com os excertos: "Pode ser que um curso online conjunto esteja surgindo como uma alternativa" (PE1).

\begin{abstract}
A grande oportunidade reside em fazer esforços para proporcionar formação com uma perspectiva internacional a TODOS os estudantes universitários e não apenas àqueles poucos que beneficiam da mobilidade. Os gabinetes de internacionalização das Universidades devem rever as suas prioridades e alianças estratégicas internacionais, manter as que são mais viáveis a longo prazo e concentrar-se na internacionalização do currículo e das atividades "em casa" (PE2, grifo nosso).
\end{abstract}

Os dados dos excertos acima apontaram que a possibilidade de mobilidade acadêmica nos ambientes virtuais foi considerada, pela maioria dos pesquisados, como uma grande oportunidade decorrente da pandemia, justamente por ampliar a participação de estudantes, de 
professores pesquisadores e administrativos, que geralmente não são beneficiados pela mobilidade acadêmica presencial. Além disso, propiciar uma internacionalização mais justa e inclusiva é essencial em um país com uma vasta extensão territorial e de muitas desigualdades sociais, como é o caso do Brasil.

A despeito das oportunidades, De Wit; Altbach (2020) também as descrevem e afirmam que as tecnologias digitais podem estar mais integradas na pesquisa e no processo de ensino e aprendizagem, aumentam as possibilidades de parcerias entre os professores e seus colegas internacionais por meio da aprendizagem colaborativa online, e outros meios de internacionalização como a do currículo e em casa.

Em relação à internacionalização em casa, Morosini (2020) destaca que é uma saída para o Brasil e países do Sul global, visto que as Instituições de Ensino não podem deixar de vivenciar a internacionalização, por possibilitar uma formação de qualidade e universal. Já Stallivieri (2020a) relatou a viabilidade da migração da internacionalização dos ambientes reais para os virtuais, denominado de virtual exchange, que pode ser realizado por meio da potencialização das tecnologias, já disponíveis nas Instituições e com a colaboração das comunidades acadêmicas nacionais e internacionais.

Ainda, em relação às perspectivas da mobilidade internacional, os dados abaixo indicam que no pós-pandemia esta deve ser ofertada tanto presencial como virtual, uma vez que não é possível atender a toda comunidade acadêmica na primeira opção devido aos custos elevados. O que pode ser reduzido minimamente no formato virtual como ressaltado por PB4. Portanto, as duas modalidades são imprescindíveis, pois as experiências resultantes da internacionalização são consideradas fundamentais para a formação de um cidadão global.

Existem vários grupos de trabalhos acadêmicos que exploram diferentes temas de cooperação e, aumentou muito a participação das instituições nas reuniões, porque elas passaram a ser virtuais. Então, se por um lado se perdeu esse aspecto da vivência, interação e interatividade presencial, por outro se abriu o leque de oportunidade para que as Universidades participem mais, porque os custos são evidentemente desprezíveis comparados com os custos de viagens e passagens e diárias. Então, talvez a gente tenha que buscar uma mescla usando essa oportunidade no futuro(PB4).

Notou-se que era possível criar pontes virtuais para ligar as pessoas, seja através do ensino dentro do nosso próprio país, mas notou-se que aquilo que a gente fazia de alguma maneira, não nessa proporção, tornou viável essas trocas. O problema é que essas trocas virtuais tiram uma das coisas mais interessantes do intercâmbio, da mobilidade, das relações internacionais acadêmicas que é exatamente a vivência cultural que se tem quando se sai do seu país de origem para viver lá fora, e ver como as outras culturas operam. Isso é uma riqueza, é uma riqueza não só no aspecto acadêmico, eu acho inclusive que esse é o menor dos aspectos, porque como há vida inteligente em Universidades brasileiras, como há coisas boas sendo feitas, ir para fora para o aluno estudar, ou receber alunos é a grande questão das relações internacionais 
acadêmicas. Porque você tem como bônus dessa sua experiência ao estudar no outro lugar, a inserção dentro de uma cultura que é diferente da sua, esseé um ativo e isso eu chamo de um commodity cultural que não tem preço, porque quando a gente faz relações acadêmicas internacionais, o que a gente está falando é de diplomacia, é diplomacia acadêmica, mas através disso que a gente leva a imagem dos nossos países, a imagem do sistema educacional. As pessoas entendam que veio para ficar sim o ensino remoto, mas é insubstituível em algum momento a humanidade vai perceber, se é que já não percebeu que é insubstituível esse contato humano seja dentro da sala de aula, seja vivendo na cultura do outro, ou com sua própria gente. A gente espera que por mais que as pessoas saibam que é possível eu e meu colega pesquisador, eu e meu colega da relação internacional, eu dar uma aula virtual, fazer o intercâmbio virtual, o COIL e tantas outras modalidades de internacionalização em casa, isso é só parte desse grande composto, porque isso não tira em nenhum momento a importância que têm a vivência in loco de outras culturas. Mas, é o que temos para o momento! Substituir as relações pessoais pelas relações mediadas por esse aparato tecnológico (PB5).

Observou-se que a mobilidade acadêmica presencial é muito enfatizada por PB5, em função das riquezas dessa experiência, tal como abordado por Machado; Santos; Costa (2020), ao indagarem que internacionalização por mobilidade acadêmica é vantajosa para os estudantes, pelo seu distinto contexto político, religioso e sociocultural, em que é possível atingir vivências relevantes. Entretanto, acrescentam que em decorrência de sua restrição a uma parcela mínima de participantes por vários fatores, a internacionalização em casa é conhecida como uma possibilidade de contribuir no desenvolvimento dessas habilidades interculturais e na formação dos acadêmicos, pois ocorre por meio das tecnologias digitais e parcerias internacionais.

A partir dos dados obtidos, articulado com os diálogos dos professores renomados da área mediante artigos e seminários online se constatou que os benefícios propiciados pela internacionalização, via mobilidade acadêmica, são inquestionáveis, portanto, a sua continuidade é indispensável. Contudo, a internacionalização nos ambientes online, virtuais, digitais, enfim mediados pela tecnologia digital também são relevantes em decorrência das condições já descritas acima e evidenciadas pela pandemia. Sendo assim, é necessário que ambas sejam promovidas e incentivadas com responsabilidade pelos governantes e Instituições de Ensino Superior, de modo a oportunizar e contribuir com uma formação plena para todos.

\subsection{DESAFIOS DA INTERNACIONALIZAÇÃO VIA MOBILIDADE ACADÊMICA NO CONTEXTO} ONLINE

Os desafios da internacionalização do Ensino Superior são extensos no contexto mundial. As diversas instituições foram afetadas de maneiras distintas, principalmente, em relação à mobilidade acadêmica, o que leva a desafios diversos. Nos excertos a seguir são apresentados alguns destes desafios relatados pelos pesquisados. 
Acredito que agora que nossos Conselhos Superiores aprovaram o ensino remoto, a ser implantado em 2020/2, previsto pelo Calendário Acadêmico Emergencial, abremse culturalmente e tecnologicamente oportunidades de aceitação de Mobilidade Virtual através do Ensino Remoto Emergencial, em tempos de Pandemia, com fortes tendências de manutenção desta opção, após vacina do COVID-19 (PB1).

O grande desafio diante desse cenário é a disseminação da informação a respeito das oportunidades existentes, a seleção de projetos relevantes e, principalmente, o bom uso dessa ferramenta (PB3).

Essa pandemia é também um grande impacto na internacionalização, mas também uma grande janela de oportunidade, pelo seguinte: esse impacto no sistema Global, aí me refiro ao sistema social, econômico, ecológico, legal, todo sistema Global de organização da sociedade. Agora, ele só pode se recuperar através de uma cooperação internacional. Essa cooperação vai ser conduzida e liderada por governos, universidades, empresas multinacionais e outras instituições intergovernamentais também, tipo família ONU. A Universidade tem papel fundamental nessa recuperação do sistema global, aportando modelos, ideias, críticas e sugestões de como essa cooperação internacional pode aportar positivamente para recuperação desse sistema, que foi absurdamente abalado. Então, eu acho que, quer queira ou não a internacionalização passa a ter um papel fundamental no sentido da cooperação internacional para recuperação do sistema impactado pela COVID-19. Então, esse é um papel que a gente tem que usar, tem que mostrar, explorar e tem que faturar no bom sentido, espero que isso abra oportunidade, editais e espaço para a gente aproveitar (PB4).

Por isso que a gente vai ter agora que reconstruir, reabrir algumas estradas que abrimos recentemente com o programa como Ciências sem Fronteiras, que colocou o Brasil no mapa da Educação Superior. Então, o desafio para mimé de novo, a gente passar da melhor maneira possível, mas rapidamente possível, todos os países por esses impedimentos econômicos que são muito concretos, eles são suprapartidários, supranacionais etc. E, quando isso passar, se descubra que o mais importante do que construir muro é construir ponte literalmente, desculpe o chavão, lugar comum, mas é disso que o mundo precisa, e as relações internacionais acadêmicas têm esse papel (PB5).

Os desafios da mobilidade internacional, neste período pandêmico, são muitos, não há possibilidade de planejar a mobilidade física internacional devido às restrições de viagem. As pessoas têm menos tempo para pensar sobre a mobilidade internacional, porque precisam desenvolver conteúdos online (PE1).

Um desafio fundamental para a mobilidade internacional, em tempos de pandemia, é que o fluxo de estudantes acadêmicos parou literalmente e deve continuar durante pelo menos um ano. Para as Universidades que concentraram a sua estratégia de internacionalização na mobilidade, esta realidade coloca em risco a própria existência do seu esforço internacional (PE2).

Como observado nos excertos anteriores, a internacionalização por meio da cooperação internacional é citada como essencial na recuperação do sistema global, nesse sentido as Instituições Superiores têm como desafio saber utilizar suas expertises selecionando e explorando as parcerias internacionais mediante os ambientes virtuais. Além disso, percebeuse que conseguir implantar a mobilidade virtual é um dos desafios destacados pela pesquisadora da região Norte, que desde 2019 vem tentando alcançar este objetivo. Superar essa crise, reduzir os impactos e restabelecer as atividades da mobilidade acadêmica também é outro de safio, que aliás para a Instituição, que tem a mobilidade como único meio de internacionalização é uma 
problemática, dado que implica em sua própria existência como sinalizado por PE2. Nesta direção, De Wit; Altbach (2020) aponta que as instituições renomadas vão se recuperar mais rapidamente, enquanto as privadas dependentes financeiramente das receitas, situadas principalmente nos países de baixa renda estão com grandes dificuldades e correm risco de serem fechadas.

Ainda, segundo os autores supracitados, o acesso ao Ensino Superior será um desafio, especialmente, para os estudantes da rede privada com mensalidades elevadas e acrescentam que a mobilidade internacional, nos países em desenvolvimento e subdesenvolvidos, o desafio será ainda maior.

De acordo com De Wit (2020; 2019), os desafios em relação às estratégias de internacionalização são múltiplos, entre esses: pressões por publicações internacionais, rankings, geração de receita, uso do idioma inglês, recrutamento de estudantes internacionais, entre outros. E para o autor, as pressões e os desafios se divergem de uma internacionalização na perspectiva inclusiva realizada em longo prazo, resultando em algumas tensões entre esta última e a internacionalização por mobilidade presencial e pesquisa em curt o prazo, considerada neoliberal.

Em relação à internacionalização do Ensino Superior, nos ambientes online, cabe destacar que não é um processo simples, exige tecnologias digitais de qualidade e acessível, políticas nacionais e institucionais de fomento, reestruturação e flexibilização do currículo, capacitação dos gestores, corpo docente e discente, conforme abordado por Morosini (2020) e Stallivieri (2020a). Esta última chama atenção para um fato relevante da virtualização da internacionalização, que é:

O risco de, mais uma vez, evidenciar as diferenças de domínio tecnológico, alfabetizaçãodigital por parte de professores e alunos, comprometimento da qualidade do ensino, carências de infraestrutura gerencial ou de domínio de gestão de novos recursos e programas. Pode-se gerar uma nova fissura entre as instituições que darão conta das demandas da internacionalização e as que não terão condições para acompanhar o novo movimento. Portanto, tem-se que agir rápido. Estudos linguísticos, aproximação de diversas comunidades universitárias, valorização de dinâmicas integradas de pesquisa podem ser objetivos e metas de uma internacionalização tão virtual quanto virtuosa, mas que necessita de urgente intervenção (STALLIVIERI, 2020a, p.3).

De fato, é necessário estar em alerta, pois a brecha digital no Brasil é imensa, conforme indicaram os dados do IBGE, em abril de 2020, em que 45,9 milhões de cidadãos brasileiros, em 2018, ainda não tinham acesso à internet (IBGE, 2020). Essa questão da conectividade, em contexto global, foi enfocada com preocupação pela Unesco (2020) e pesquisadores de modo 
geral, visto que a crise decorrente da pandemia tem acentuado as desigualdades socioeconômicas.

Diante deste contexto, é necessário ter cuidado na implementação dos projetos e programas de internacionalização, nos ambientes online, para que não se pratiquem as mesmas falhas da mobilidade presencial, citadas por Stallivieri(2020a, p.3) ao afirmar "que priorizaram a oferta de programas excludentes e elitistas, nos quais somente estudantes com recursos, domínio de línguas, capacidade financeira, engajamento familiar, entre outros fatores conseguiram realizar uma experiência internacional". Nesse sentido, De Wit (2020) e Morosini (2017) reforçam a necessidade de uma aprendizagem global e para todos, sem o equívoco de considerar a internacionalização como meta em si mesma, mas sim como um meio de melhorar a qualidade do ensino, da pesquisa e da extensão.

A partir dos relatos dos pesquisados e teóricos da área se pode conjecturar que os desafios da mobilidade acadêmica internacional, ou seja, da internacionalização do Ensino Superior, em tempos de ensino online e no contexto de pandemia são imensos e distintos para as Universidades, afinal são realidades diversas. O que exige muita reflexão, união e cooperação das comunidades acadêmicas nacionais e estrangeiras para que superem esses desafios e consigam de fato realizar um processo de internacionalização abrangente, indo na direção do que enfatiza De Wit (2020, p. 5): "trabalhar para uma aprendizagem internacional e intercultural inclusiva para todos significa que nos tornamos mais respeitosos com os diversos contextos, agendas e perspectivas em uma escala global”.

\section{CONSIDERAÇÕES FINAIS}

A situação pandêmica é muito complexa, portanto, ainda não foi possível estabelecer um protocolo de como as Instituições de Ensino deverão agir em relação à internacionalização do Ensino Superior. Assim sendo, este estudo teve como objetivo contribuir com as discussões e reflexões sobre a mobilidade acadêmica internacional, no contexto atual de ensino online.

A pesquisa permitiu concluir que a internacionalização do Ensino Superior foi extremamente impactada pela pandemia do COVID-19, principalmente, a mobilidade acadêmica internacional, considerada a principal estratégia de internacionalização das Instituições de Ensino Superior no cenário global. Esta foi interrompida durante esse período e deve sofrer uma retração nos anos seguintes, justamente por causa da crise econômica.

A partir da análise dos dados foi possível verificar que as perspectivas da mobilidade acadêmica, no contexto de pandemia e ensino online, vêm ocorrendo por meio do intercâmbio 
e mobilidade acadêmica virtual, denominada internacionalização em casa. Que por sinal, foi vista pela maioria dos pesquisados como uma grande oportunidade decorrente da pandemia, em função de possibilitar uma formação internacional e intercultural a uma quantidade maior de participantes sem sair do país.

Ou seja, as barreiras impostas pela pandemia se transformaram em uma perspectiva para efetivar e elevar a internacionalização em casa, pois facilita a participação de mais pessoas, além de reduzir os gastos relacionados a diárias, passagens, vistos, entre outros. Todavia, não significa que a mobilidade acadêmica presencial deva ser substituída pela virtual, ao contrário, os dados indicam que ambas precisam ser ofertadas nas Instituições de Ensino, de forma integrada, até porque pertencem a um conjunto de ações do processo de internacionalização do Ensino Superior.

A análise dos resultados evidenciou que os desafios da internacionalização do Ensino Superior são vastos no cenário mundial. Notou-se que as Instituições de Ensino Superior devem atuar com protagonismo, se organizando estrategicamente para conseguir superar a crise o mais breve possível, implementando as ações da internacionalização e se beneficiando dos ambientes virtuais, selecionando e explorando a cooperação internacional. Percebeu-se que uma infraestrutura adequada, formação dos professores e estudantes são muito importantes para conseguir lidar e atingir os objetivos da internacionalização no ambiente online. Ademais, o apoio governamental é considerado crucial nesse processo, uma vez que as desigualdades sociais estão mais evidentes, a brecha digital é enorme, principalmente, no Brasil, logo são necessárias políticas públicas, estudos e planejamentos para alcançar a democratização do acesso à internet, propiciando a inclusão digital dos estudantes e não a sua exclusão.

Por fim, foi possível observar que as perspectivas e desafios estão muito relacionados, e que há um consenso entre os pesquisados e a literatura apresentada no intuito de pensar uma internacionalização do Ensino Superior mais justa e inclusiva, que cumpra efetivamente os seus propósitos de solidariedade, empatia, respeito ao próximo e as diferenças culturais, contribuindo com uma educação universal e de qualidade para todos os cidadãos.

\section{REFERÊNCIAS}

BARANZELI, Caroline. Modelo de internacionalização em casa - IaH. In: Marília Morosini (Org). Guia para a Internacionalização Universitária. Porto Alegre: EDIPUCRS, 2019. Edição do Kindle.

BARANZELI, Caroline.; MOROSINI, Marília Costa; WOICOLESCO, Vanessa Gabrielle. "A chave está na troca" - estudantes de mobilidade como vetores da internacionalização em 
casa. Série-Estudos - Periódico do Programa de Pós-Graduação em Educação da UCDB, p. 253-274, 2020.

BEELEN, Jos.; JONES, Elspeth. The European Higher Education Area. The European Higher Education Area, p. 59-72, 2015.

BITTENCOURT, Zoraia Aguiar. Mobilidade Acadêmica e Engagement Estudantil como estratégia de Internacionalização. In: Marília Morosini (Org). Guia para a Internacionalização Universitária. Porto Alegre: EDIPUCRS, 2019. Edição do Kindle.

BOGDAN, Robert; BIKLEN, Sari. Investigação qualitativa em Educação: Uma introdução a teoria e aos métodos. - Portugal: Porto Editora, 1994.

CERI JONES, Hywel. Celebrating 30 years of the Erasmus programme. European Journal of Education, 52(4), 558-562, 2017.

DE WIT, Hans; ALTBACH, Philip. G. The Impact of COVID-19 on the Internationalization of Higher Education, Revolutionary or not? Internationalization of Higher Education - Policy and Practice, 2, p. 5-18, 2020.

DE WIT, Hans. The Future of Internationalization of Higher Education in Challenging Global Contexts. IETD- Educação Temática Digital, v. 22, n. 3, p. 538-545, 2020.

DE WIT, Hans. Internationalization in higher education: a critical review. SFU Educational Review, v. 12, n. 3, p. 9-17, 2019.

DESLAURIERS, Jean-Pierre. A Indução Analítica. In. POUPART, J. et al. A pesquisa qualitativa: enfoques epistemológicos e metodológicos. Petrópolis: Vozes, 2008.

GIL, Antônio Carlos. Como elaborar projetos de pesquisa. 4.ed. São Paulo: Atlas, 2002.

IBGE. Pesquisa Nacional por amostra de Domicílios Contínua. Acesso à internet e à televisão e posse de telefone móvel celular para uso pessoal 2018. Disponível em: < https://www.ibge.gov.br/estatisticas/sociais/populacao/17270-pnad continua.html?edicao=27138\&t=resultados $>$. Acesso em 12 jul. 2020.

KENSKI, Vani Moreira. Tecnologias e Ensino Presencial e a Distância. Campinas, SP: Papirus, 2003.

KNIGHT, Jane. Internationalization Remodeled: Definition, Approaches, and Rationales. Journal of Studies in International Education, v. 8, n. 1, p. 5-31, 2004.

KNIGHT, Jane. Concepts, rationales, and interpretive frameworks in the internationalization of higher education. In: Deardorff et al. The Sage Handbook of international Higher Education. Thousand Oaks: SAGE Publications, 2012.

LEASK, Betty. Internationalizing the Curriculum. London: Routledge, 2015.

MACHADO, Karen Graziela Weber.; SANTOS, Priscila Kohls; COSTA, Camila Schwanke. As contribuições das tecnologias digitais para a internacionalização da Educação Superior em 
casa e a construção da cidadania global. Revista Cocar, v. 14, n. 29, p. 700-722, 2020.

MARCONDES, Nilsen Aparecida Vieira.; BRISOLA, Elisa Maria Andrade. Análise Por Triangulação De Métodos: Um Referencial Para Pesquisas Qualitativas. Revista Univap, v. 20, n. 35, p. 201, 2014.

MORAN, José. Contribuições para uma pedagogia da educação on-line José Moran. p. 39-50, 2003. Disponível em:

http://www.eca.usp.br/prof/moran/site/textos/educacao_online/contrib.pdf. Acesso em: 19 set. 2020.

MOROSINI, Marília Costa. Estado do conhecimento sobre internacionalização da educação superior: conceitos e práticas. Educar em Revista, n. 28, p. 107-124, 2006. Disponível em: https://www.scielo.br/pdf/er/n28/a08n28.pdf. Acesso em: 19 set. 2020.

MOROSINI, Marília Costa. Qualidade da educação superior e contextos emergentes. Avaliação: Revista da Avaliação da Educação Superior (Campinas), v.19, n.2, pp.385405, 2014. Disponível em: https://doi.org/10.1590/S1414-40772014000200007. Acesso em: 21 set. 2020.

MOROSINI, Marília Costa. Internacionalização da Educação Superior e integração acadêmica. Conferências UFRGS, Porto Alegre: UFRGS, dez. 2017. Disponível em: https://lume.ufrgs.br/handle/10183/172865. Acesso em: 25 set. 2020.

MOROSINI, Marília Costa.; NASCIMENTO, Lorena Machado. Internacionalização da Educação Superior no Brasil: A produção recente em teses e dissertações. Educação em Revista, v. 33, 2017. Disponível em: https://www.scielo.br/scielo.php?pid=S010246982017000100109\&script=sci_abstract\&tlng=pt. Acesso em: 10 ago. 2020.

MOROSINI, Marília Costa et al. Rumo da internacionalização no ensino superior pós pandemia. Youtube. Disponível em: https://www.youtube.com/watch?v=2jrjVbWKc_M Acesso em: 02 set. 2020.

OCDE. Education ata Glance 2018: OECD Indicators, 2018. Brazil - Country Note. Tradução de Walkíria de Moraes Teixeira da Silva. OECD Publishing, 2018. Disponível em: http://download.inep.gov.br/acoes_internacionais/estatisticas_educacionais/ocde/education_at _a_glance/Country_Note traduzido.pdf. Acesso em: 14 ago. 2020.

OCDE. "What is the profile of internationally mobile students?", in Education at a Glance 2020: OECD Indicators, OECD Publishing, Paris, 2020. Disponível em: https://doi.org/10.1787/974729f4-en. Acesso em: 20 set. 2020.

PALLOFF, Keith Pratt.; Rena M. Lições da sala de aula virtual: as realidades do ensino online [recurso eletrônico]/ Rena M. Palloff, Keith Pratt. 2. ed. Porto Alegre: Penso, 2015. Edição do Kindle.

RAMOS, Milena. Yumi. Internacionalização da pós-graduação no Brasil: lógica e mecanismos. Educação e Pesquisa, v. 44, n. 0, p. 1-22, 2018. Disponível em: https://www.revistas.usp.br/ep/article/view/143491. Acesso em: 5 set. 2020. 
RAPANTA, C. et al. Online University Teaching During and After the Covid-19 Crisis: Refocusing Teacher Presence and Learning Activity. Postdigital Science and Education, p. 1-23, 2020. Disponível em:

https://www.ncbi.nlm.nih.gov/pmc/articles/PMC7339092/pdf/42438_2020_Article_155.pdf. Acesso em: 20 out. 2020.

SANTOS, Priscila Kohls. Permanência na Educação Superior: desafios e perspectivas. Brasília: Cátedra UNESCO e Juventude, Educação e Sociedade, 2020. Disponível em: https://socialeducation.files.wordpress.com/2020/05/kohls-permanencia-na-educacaosuperior_web.pdf. Acesso em: 10 out. 2020.

STALLIVIERI, Luciane. Compreendendo a internacionalização da educação superior. Revista de EDUCAÇÃO do Cogeime, v. 26, n. 50, p. 15, 2017.

STALLIVIERI, Luciane. Covid19: Quo Vadis? Internacionalização da Educação Superior: dos Ambientes Reais para os Ambientes Digitais, 2020. Disponível em:

https://www.linkedin.com/pulse/covid19-quo-vadis-luciane-stallivieri. Acesso em: 20 ago. 2020a.

STALLIVIERI, Luciane. International virtual education needs greater support. University World News, 2020. Disponível em:

https://www.universityworldnews.com/post.php?story=20200518150642841. Acesso em: 20 ago. 2020 b.

UNESCO. Pandemia expõe importância de universalizar acesso à Internet no mundo.

Disponível em: https://nacoesunidas.org/unesco-pandemia-expoe-importancia-deuniversalizar-acesso-a-internet-no-mundo/. Acesso em: 15 set. 2020.

VALENTE, José Armando. Tecnologias e Educação a Distância no Ensino Superior: Uso de Metodologias Ativas na Graduação. Trabalho \& Educação, p. 97-113, 2019. Disponível em: https://periodicos.ufmg.br/index.php/trabedu/article/view/9871. Acesso em 12 set. 2020. 